\title{
Women's Decision-Making Autonomy in Maternal Health Service Utilization and Associated Factors among Reproductive Age Women in Southern, Ethiopia
}

kirubel eshetu ( $\square$ kiruesha2@gmail.com )

wolaita sodo university https://orcid.org/0000-0002-1303-6761

Belete Gelaw

Wolaita Sodo University

Tadele Lankrew

Wolaita Sodo University

Andualem Assefa

Wolaita Sodo University

Tsegaye Demeke

Wolaita Sodo University

\section{Research article}

Keywords: women, decision making, autonomy, maternal health service utilization, southern Ethiopia

Posted Date: May 17th, 2021

DOl: https://doi.org/10.21203/rs.3.rs-521248/v1

License: (c) (1) This work is licensed under a Creative Commons Attribution 4.0 International License.

Read Full License 


\section{Abstract}

\section{Background}

Women autonomy is ability of women to make self-regulating decision to meet their requirement without any one initiation. Women who can autonomously decide on their health utilized maternal health care is poor, even though a lot of effort has been made. Only less than $32 \%$ of developing countries women have decision making power to visit maternal health service.

Objective

To assess the women decision making autonomy in their maternal health service utilization and its associated factors among reproductive age group women in southern Ethiopia, from March1, 2019 to March 30, 2019.

Methods and material

A cross-sectional study design was conducted. Data were analysed using descriptive statistical tests and binary logistic regression was used. All independent variables with $p$-value of $<0.25$ at bivariate analysis were included in multivariate model to determine the predictors of the outcome variable, and to control the confounding factors. For all statistical tests, a P value of $<0.05$ was a cut off point for statistical significant.

Results

prevalence of women decision making autonomy in their maternal health service utilization was $58.2 \%$ $[(A O R=58.2 \%(95 \% \mathrm{Cl}(54.2-62.0)$. Number of family size $2.2[\mathrm{AOR}(95 \% \mathrm{Cl})=2.2,95 \% \mathrm{Cl}(1.3-3.72)]$, occupation, 4.3 [AOR $(95 \% \mathrm{Cl})=4.395 \% \mathrm{Cl}(1.10-9.3)$ ] economic status, $2.2[\mathrm{AOR}(95 \% \mathrm{Cl})=2.2,95 \% \mathrm{Cl}$ (1.3-3.72)] respondent age above $354.8[\mathrm{AOR}(95 \% \mathrm{Cl}=4.8,95 \% \mathrm{Cl}(2.3-10)]$ were the factors significantly associated with decision making autonomy.

Conclusion

prevalence of women decision making autonomy in their maternal health service utilization was $58.2 \%$ which was found to be low. Decision making autonomy was more common with low income, large family size, respondent age and lack women occupation. Improved the women's decision making by giving Health education on the importance of maternal health services and gender equality recommended to reducing the problem.

\section{Background}

Women's autonomy is ability of women's to make self-regulating decision to meet requirements without any one initiation (Yuji S. et al., 2018). Autonomy of deciding for her maternal health service utilization 
means the capacitate of a woman to make self-regulating decision regarding for her reproductive wants and to look for maternal health services such as antenatal care (ANC), postnatal care (PNC), and service delivery care (SDC) (Sadik A, 2017).

In particular findings suggest autonomy from no contribution to significantly utilized maternal health service including antenatal care and institutional delivery (GDPC, 2018). Despite various efforts has been made to enhance women autonomy majority of women in Africa has no decision making power to utilized various reproductive maternal health service during pregnancy and child birth (Bhandari T., 2015). Illiteracy, wealth index, socio cultural habits religious and lack of information were attributed to low decision making on health care in women (Mihiretu A. and Mengistu M, 2017). Good maternal and child health outcome observed among individuals who have autonomous decision power as compare to their counterpart (Yohannes D., 2017).

In developing country, women's Decision making power regarding reproduction and sexuality is extremely restricted and most of the time Decisions on maternal health care are frequently made by partners or other relatives; which affects women's to visits health facility (Dabere $\mathrm{N}$ et al., 2014).

In developing country women are Less autonomous to decide to visit health facility for maternal health service (Ghose B. et al., 2017). Absence of autonomy in decision making directly result in poor utilization of maternal health service and this situation amends maternal morbidity and mortality through delay (sadik A., 2017).

Indonesia Demographic and Health Survey (DHS) showed that $23 \%$ of teenage mothers reported their husbands or others made decisions for their health care which affects women to go health facility by them self (Ramesh A., 2016)

Studies indicate that $23 \%$ of teenage mother claimed that their husband or other person decide on their health service this pave for three delays that deadly affect maternal wellbeing. In developing country extent of women decision making to seek maternal service ranges from 21.9-31.6\% (Chima.V, 2018). Without increasing autonomy increasing level of women decision making power archiving sustainable development goal to reduce maternal and child mortality seems impossible (USAID, 2017 ; WHO, 2016).

Ethiopian demographic health survey 2016 shows that only 15.4\% of where autonomous in house decision make alone and use health service to meet reproductive health goal, including safe motherhood women who did not participate in any household decision and those who have not freedom movement were much less likely to receive antenatal care $(44 \%)$ delivery care $(24 \%)$ from skilled provider and postnatal cheek up (8\%) (CSA and ICF, 2016).

The extent of women decision making power to visit to visit maternal health service and its associated factors is not known in the study area therefor we aim to assess women decision making power for maternal health service and to identify it predictors of in southern, Ethiopia . 


\section{Methods}

\section{Study setting and Period}

The study was conducted in southern, Ethiopia from March 1, 2019 to March 30; 2019.

\section{Study Design and Population}

Community Based Cross Sectional Study was conducted among all reproductive age group of married women in southern, Ethiopia.

\section{Sample Size Determination and Sampling Technique}

To determine the sample size for studying factors associated with women autonomy of decision making regarding their maternal health service utilization, the formula for single population proportion was used and the following assumption was made. Significance level of $95 \%$ confidence interval and $5 \%$ margin of error were taken the study on factors associated with women autonomy of decision making regarding their maternal health service utilization in, Southern Nations, Nationalities and Peoples Republic, Ethiopia. $58.4 \%$ of women have autonomy on decision making similar as study conduct in Wolaita and Dawro zones, Southern Ethiopia (Mihiretu A. and Mengistu M, 2017)Let as women autonomy of decision making regarding their maternal health service utilization is the . Prevalence $=58.4 \%$; and use $10 \%$ non-response rate.

Sample size is calculated by using the single population proportion formula as follows.

Where, $n=$ desired sample size, $p=$ expected prevalence of women autonomy of decision making $58.4 \%$; $z=$ confidence interval $-95 \%, d=$ desired precision $-5 \%, n=$ required sample size, $N=$ final sample size and Design effect 1.5

$$
n=\frac{1.96^{2} * .584(1-.584)}{0.05^{2}}=\frac{3.8416 * . .584 * .416}{.0025} \cong 373.3
$$

, $=373.3$ then to get final sample size $(N)$, use non-response rate $(10 \%), N=10 \% * n+n, N=10 \%$ of $373+$ $373,=37.3+373=410 * 1.5=615 \mathrm{~N}=615$.

\section{Data Collection Procedures}

A structured interviewer administered questionnaire which was Adapted from the EDHS, 2016 and different literatures (Tulsi R., 2015), (Deependra K, 2012),(Osamor P and Grady C, 2016).Were used to collect data. The questionnaire was including all the questions that assess women autonomy of decision making on maternal health service utilization. Data was collected by interviewing eligible subjects using a 
pre-tested structural questionnaire. The tool was prepared in English version and it was translated to Amharic, Amharic again translated back to English language to check consistency.

\section{Data Processing and Analysis}

All data were checked for completeness and internal consistency by cross checking and coded and entered onto EPI-DATA version 3.1 and then exported to SPSS 20.0 for analysis. Principal component analysis was conducted to produce wealth quintiles and reveal socioeconomic status of the households. Multi co-linearity test was carried out to see the correlation between independent variables using standard error. Model fitness was checked by using Hosmer -Leme show. Descriptive statistics was used to describe the study population in relation to relevant variables. Both bivariable and multivariable logistic regression models were used to identify factors associated with the outcome variable. In order to enter factors in final multivariable model, only variables with $p$-value $<0.25$ during bivariable analyses were entered into the multiple logistic regression models. Odds Ratio along with $95 \%$ Confidence Intervals was estimated to measure the strength of the association between dependent and independent variables. Levels of statistical significance were considered at $p$ - value less than 0.05 .

\section{Ethical Considerations}

Ethical clearance was obtained from the Institutional health research ethics review committee (IHRERC) Haramaya University College of Health And Medical Sciences. All procedure was conducted after completing permission from the postgraduate office of Haramaya University. After permission letter obtained from school of graduate office, letter was submitted to each Zone. An informed, voluntary, written and signed consent was obtained. Participants were informed clearly about the purpose and benefits of the study and written informed consent was obtained from the participants. Those who are signed written consent were only participating in the study and the confidentiality of respondents was maintained throughout the research process by giving code for participant. Personal privacy and cultural norms were respected. The respondents were having the right not to participate in study or withdraw from the study at any time/stage of interview.

\section{Operational Definitions}

Women decision making Autonomy in their maternal health service utilization: is dictated as "Yes" on the options women are participate in health service utilization if she have the right to use health care, freedom of movement and if she has right to use house hold purchases. If a woman is decide alone and with their husband jointly they are autonomous if only husband and someone give decision she is not autonomous in decision making (EDHS, 2016). 
Maternal health service refers a service given by skilled health professional before pregnancy, during pregnancy and postpartum period (WHO, 2018).

Antenatal Care: - a care provided by skilled health-care professionals to women in order to ensure the best health conditions for both mother and baby during pregnancy (WHO, 2018)

Post natal care: a care service given to the delivered mother by skilled birth attendance after birth (WHO, 2018).

Delivery care service: a care given by skilled health care professionals to women during child birth (WHO, 2018).

Knowledgeable: - those women who scored at least $84 \%$ and above in knowledge questions.

Moderately knowledgeable: - those women who score $50-84 \%$ of knowledge questions.

Less knowledgeable: - those women who scoreless than $50 \%$ of knowledge questions (Dabere $\mathrm{N}$ et al., 2014).

\section{Results}

Out of 615 respondents expected to participate in the study 588 respondents were interviewed which makes a response rate of $96 \%$. The mean age of the respondents was 30.23 with SD \pm 6 years. Majority of respondents 208 (35.4\%) were attained secondary education and 552 (93.9\%) were in monogamous marriage. Around one-third of 200 (34\%) were high percentile group of wealth. Almost half of $248(44.9 \%)$ respondents have family size less than five (Table1).

Majority of 496 (84.4\%) the respondents have exposure to media like watching TV and also $92(15.6 \%)$ respondents were listening to radio. Half of respondents 294 (50\%) have poor knowledge on maternal health service utilization and decision making autonomy (Table2).

Almost half (43.4\%) have decided by themselves to go health facility and most of respondents have the right to participate in family health care $33(43.4 \%)$ alone and $371(56.6 \%)$ jointly with husband. Besides to these most of women visit to health facility by themselves $33(5.6 \%)$ jointly with husband $371(63.1 \%)$ the rest 168 (28.6) respondents can't visit without their husband permission. Related to place of delivery the majority of respondents $339(57.7 \%)$ can't decide place of delivery $103(17.5 \%)$ decide jointly with husband. Less than half of 194 (33.0\%) only decided by husband. Majority around 533(90\%) of respondents were note have post natal care (Table3).

Majority of respondents 270 (45.9\%) get permeation for spending money. Similarly $72(12.8 \%)$ respondent decided on her earning. Also only $92(15.6 \%)$ respondents can decide on her husband earning jointly 293 (49.8\%) husband alone 197 (46.8\%).majority of respondents can't decide alone for buying medication and Majority of respondents can't decide alone to go to outside house compound 97 (16.5\%) 
majority of respondents decide jointly $291(49.5 \%)$ and only husband 194 (33\%). Similarly, $128(21.8 \%)$ of study participants decide in visiting their family by themselves, whereas $276(46.9 \%)$ made decisions jointly and only husband185 (31.3\%) and also majority 259 (44.0\%) of respondents decide together to go public places (Table4).

The prevalence of women decision making autonomy is $58.2 \%$ [(AOR= 58.2\% (95 \% Cl (54.2- 62.0) (Figure1).

Age, educational status of respondents, educational status of respondents husband, family size, wealth index, respondent occupational status, husband occupational status, media access, marital status, were analysed in bivariable analysis, age of respondent, educational status of respondents, educational status of respondents husband, family size, wealth index, respondent occupational status, husband occupational status, distance to health facility, media access, marital status significantly associated with health care decision making autonomy in bivariate analysis (Table5).

In multivariable analysis age of respondent, wealth index, women occupation, family size, women educational status were significantly associated with women decision making autonomy on their maternal health service utilization. Participants who have age category more than 35 years $4.8[\mathrm{AOR}(95 \% \mathrm{Cl})=4.8(2.3-10)]$ times more likely autonomous in decision making autonomy in maternal health care utilization as compared to less than 25 years. Also women's in age category of 24-35 years 9.5[AOR $(95 \% \mathrm{Cl}=9.5(3.10-22.46)]$ times more likely participate in decision making autonomy than less than 24 years. Participants who have employed 18.5 [AOR $(95 \% \mathrm{Cl})=18.5,95 \% \mathrm{Cl}(4.951-69.294)]$ times more likely participate in decision making autonomy to maternal health care utilization as compared to house wife's. Those women with one-two family size were 2.2 [AOR (95\% Cl=2.2 (1.3-3.7)] times more likely have decision making autonomy on maternal health care utilization than those who have family size more than five children.

The richest women's was found strong significant associations with women's decision making autonomy on maternal health service utilization than those who were in reach category women's have 2.2 [AOR (95\% $\mathrm{Cl})=2.2,95 \% \mathrm{Cl}(1.3-3.72)]$ times more likely they were autonomous in decision making maternal health service utilization than in the lowest category (Table6).

\section{Discussion}

This study showed that overall prevalence of women decision making autonomy in their maternal health service utilization among reproductive age group women was $58.2 \%(95 \%) \mathrm{Cl}=(54.2-62.0)$. The following factors were significantly associated with women decision making autonomy like respondent age, family size, occupation and economic status. The prevalence of women decision making autonomy among reproductive age group women in this study was found to be $58.2 \%$ This findings was higher than that of a study conducted in Asian country Nepal (27.3\%), Bangladesh (45.7\%) and India (49\%). The presence of low prevalence of women decision making in this area might be due to traditional believes and tribes Most of decision made by male partner and family members. Related to African studies this 
study was lower than study done in Nigeria 62\% (Abubakar sadik umer 2017) and in Wolaita and Dawro 58.4\% (Mihiretu a. and Mengistu M., 2018) and in Mizan Aman (67.2\%) (Belay. et.al, 2016). This discrepancy could be due to the difference in the sample size. In this study Participants who with age group of above 35 years were more autonomous in decision making than less than 24 years and women's with age group of 25-34 years were more autonomous in decision making than less than 24 years. Another study done in out of our country in Nigeria shows women's above 35 years has 1.82 times more autonomous in decision making than younger women's (pauline $O$. and Christine $G, 2018$ ). This study also indicates that family size associated with women's decision making autonomy As family size increases, the probability of the woman participating in health care decision making decreases. In this study, women with a family size of more than five have a 1.5 times more likely chance of participating in health care decision making as compared to women with a family size of less than five persons (pauline O. and Christine G, 2018).

Those participants who had a highest wealth index household were 2.2 times more likely autonomous in decision making maternal health service utilization than their counterparts. This reports agrees with research conducted in eastern Ethiopia shows that women In higher wealth index 3.5 times more likely autonomous in decision making than lower (Tiruneh F.et.al,2017). This study also showed that employment status have significant association with women decision making autonomy in their maternal health service utilization women in employed women 4.3 times more likely autonomous in decision making than house wife's this is in lined with a study done in eastern Ethiopia which identify employed women's 4.10 times more likely to have decision making autonomy in their maternal health service utilization (Belay., et.al, 2016).

\section{Conclusions}

This study shows that prevalence of women decision making autonomy in maternal health services was poor. Age, women occupation, family size, wealth index were significantly associated with women decision making autonomy in maternal health services utilization. Every woman has the right to participate in decisions making about her own health care. More than half participants have no role in making health care decisions. Husbands/partners play a major role in making health care decisions about their wife's. The majority of women with the highest health care decision making autonomy in southern Ethiopia also have significantly higher odds of having high wealth index, high age, small family size, women and employment. Even if a household has adequate resources, a woman's limited participation in household decision making leads to low uptake of maternal health services. This study conclude that a woman's health care decision making autonomy is broadly influenced by participants age, household economy, family size, and occupation.

\section{Abbreviations}

ANC: antenatal care AOR: Adjusted odds ratio CDC: communicable disease controls Cl: Confidence Interval COR: Crude odds ratio EDHS: Ethiopian Demographic Health Survey MDG: Millennium 
Development Goal MHS: Maternal Health Service PNC: postnatal care

SD: standard deviation SDC: service delivery care USAID: United States Agency for International Development WHO: world health organizations.

\section{Declarations}

\section{Ethics Approval and Consent to Participate}

Ethical issues were approved by Haramaya University College of health and medical sciences institutional health research ethical review committee. Letters of permission and support were provided to the respective Region and Zones from Haramaya University. The Letter was provided to each region and Zones administrative body to get their informed consent for data collection before starting to collect data. Prior to administering the questionnaires, the objectives of the study were clearly explained, informed voluntary written and signed consent were obtained. Confidentiality was ensured. To keep the anonymity of study participants, code numbers rather than personal identifiers were used.

\section{Consent for Publication}

This part is not applicable because the manuscript contains no any individual person's data in any form (including individual details, images or videos).

\section{Funding}

Not applicable

\section{Acknowledgements}

We would like to express our heartfelt gratitude to all selected study site officials whom we have communicated, and indorsed as to conduct this study. Our special thanks also extended to the study participants, data collectors, supervisors and staffs.

\section{Authors' contributions}

All authors have made substantial contributions in this study. The corresponding author conceived and designs the study, did the literature search, coordinated the write-up, participated in data analysis, editing and submission of the article. All co-author's participated in literature search, analysis and interpretation of data, drafting the article and revising it for important intellectual content and approve the final version of the manuscript.

\section{Availability of data and materials}

The data sets used and/or analysed during the current study are available from the Corresponding author upon reasonable request. 
Competing of Interests

The authors declared that they have no competing interests.

\section{References}

1. Alemayehu M and Meskele M. (2017) Health care decision making autonomy of women from rural districts of Southern Ethiopia: a community based cross-sectional study. International journal of women's health 9: 213.

2. Belay D., Zelalem Birhanu Mengesha, Manay Kifle Woldegebriel, et al. (2016) Married women's decision making power on family planning use and associated factors in Mizan-Aman, South Ethiopia,. BMC Women's Health.

3. Bhandari T. (2015) WOMEN'S AUTONOMY AND UTILIZATION OF MATERNAL HEALTH SERVICES IN KAPILVASTU DISTRICT NEPAL.

4. Chima V. (2018) Women autonomy and maternal healthcare services utilization among young evermarried women in Nigeria. International Journal of Nursing and Midwifery 10: 62-73.

5. CSA and ICF. (2016) Ethiopia Demographic and Health Survey 2016: KeyIndicators Report. Addis Ababa, Ethiopia, and Rockville, Maryland, USA. CSA and ICF.

6. Dabere N., Abebe Gebremariam, Abera M, et al. (2014,) Factors associated with women's autonomy regarding maternal and child health care utilization in Bale Zone. BMC Women's Health

7. Deependra K. (2012) WOMAN'S AUTONOMY AND HUSBAND'S INVOLVEMENT IN MATERNAL HEALTH CARE UTILIZATION IN NEPAL.

8. Edward K., Tanle KwakuKissah and Korsah Joshua. (2017) Women's Health Decision-Making Autonomy and Skilled Birth Attendance in Ghana.International Reproductive Medicine: 9

9. (2018) Assessing the Role of Women's Autonomy and Acceptability of Intimate Partner Violence on Maternal Health Care Utilization in 63 Low- and Middle-Income Countrie. HCI WORKING PAPER 004.

10. Ghose B., Da Feng, Shangfeng Tang, et al. (2017) Women's decision-making autonomy and utilisation of maternal healthcare services: results from the Bangladesh Demographic and Health Survey. BMJ Open.

11. Lee R., Kumar Jessica and Amer A-N. (2017,) Women's Healthcare Decision-Making Autonomy by Wealth Quintile from Demographic and Health Surveys (DHS) in Sub-Saharan African Countries,. International Journal of Women's Health and Wellness 3

12. Mihiretu A. and Mengistu M. (2017) Health care decision making autonomy of women from rural districts of Southern Ethiopia. International Journal of Women's Health

13. Mussie A., Kiday Hailesellasie, Gebrezgabiher Biruh, et al. (2014) Married women's autonomy and associated factors on modern contraceptive use in Adwa Town, Northern Ethiopia. Science Journal of Public Health 
14. Nigatu D, Gebremariam Abebe, Abera Muluemebet, et al. (2014) Factors associated with women's autonomy regarding maternal and child health care utilization in Bale Zone: a community based cross-sectional study. BMC women's health 14: 79.

15. Osamor P and Grady C. (2016) Women's autonomy in health care decision-making in developing countries: a synthesis of the literature. International journal of women's health 8: 191.

16. Osmar P. and Grady C. (2018) FACTORS ASSOCIATED WITH WOMEN'S HEALTH CARE DECISIONMAKING AUTONOMY: EMPIRICAL EVIDENCE FROM NIGERIA. HHS Public Access: 50.

17. Ramesh A. (2016) Effect of Women's autonomy on maternal health service utilization in Nepal. $B M C$ Women's Health: 26.

18. Sadik A. (2017) Women Autonomy and the use of Antenatal and Delivery Services in Nigeria. MOJ Public Health 6: 00161.

19. sadik A. U. (2017) Women Autonomy and the Use of Antenatal and Delivery Services in Nigeria.MOJ Public Health

20. Senarath U., Nalika Sepali and Gunawardena. (2009,) Women's Autonomy in Decision Making for Health Care,. Asia-Pacific Journal of Public Health in South Asia, 21: 2.

21. Shanta P., Gyanesh Lama and Haenim Lee. (2016) Effect of women's empowerment on their utilization of health services, International Social Work.

22. Shrestha B. (2012) Gender Study on Knowledge and Decision Making on Maternal Health Care in Nepal,. ORIGINAL RESEARCH ARTICLE

23. Tiruneh $\mathrm{F} \mathrm{N}$, Chuang K-Y and Chuang Y-C. (2017) Women's autonomy and maternal healthcare service utilization in Ethiopia.BMC health services research 17: 718.

24. (2017) Women's Empowerment and the Use of Antenatal Care Services in Southeast Asian Countries.DHS WORKING PAPERS. 129.

25. (2016) The Global Strategy for Women's, Children's and Adolescents' Health.

26. (2018) Fact sheets on sustainable development goals: health targets.

27. Yohannes D. (2017) Women's autonomy and reproductive health-care-seeking behavior in Ethiopia,. Women \& Health.

28. Yuji S., Roger Antabe, Kilian Nasung Atuoye, et al. (2018) Married women's autonomy and postdelivery modern contraceptive use in the Democratic Republic of Congo. jornal of BMC Women's Health

\section{Tables}

Due to technical limitations, table $1,2,3,4,5$ is only available as a download in the Supplemental Files section.

\section{Figures}




\section{Women dicission making autonomy}

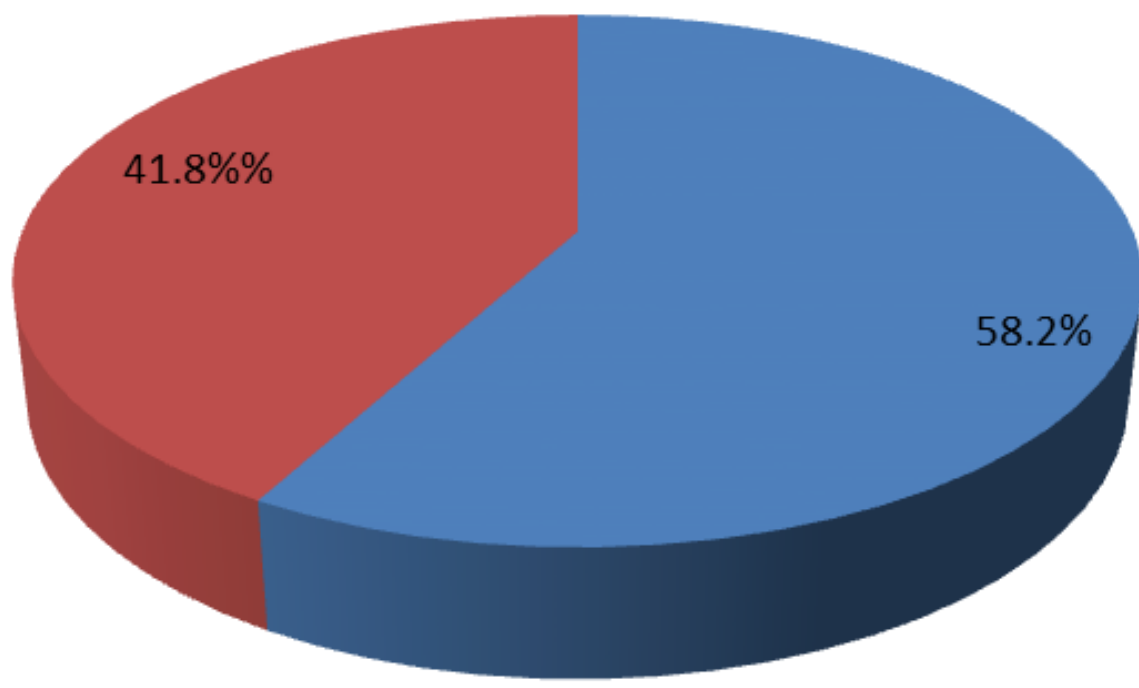

Automous

not autonomous

\section{Figure 1}

level of Women's Decision-Making Autonomy in Maternal Health Service Utilization and Factors Associated among Reproductive Age Women in Southern, Ethiopia $(n=588)$.

\section{Supplementary Files}

This is a list of supplementary files associated with this preprint. Click to download.

- Tables.docx 